\title{
Lymphocytic myocarditis in an overlap syndrome of systemic sclerosis and polymyositis
}

\author{
Salomé Garcia ${ }^{1}\left[\right.$ - Frederico Rajão Martins ${ }^{2} \cdot$ Daniela Oliveira $^{1} \cdot$ Beatriz Samões $^{3} \cdot$ Ana Martins $^{1} \cdot$ Georgina Terroso $^{1}$. \\ Lúcia Costa ${ }^{1}$
}

Received: 11 August 2021 / Revised: 6 September 2021 / Accepted: 7 September 2021 / Published online: 13 September 2021

(c) International League of Associations for Rheumatology (ILAR) 2021

\section{Presentation}

We report the case of a 29-year-old female with the diagnosis of an overlap systemic sclerosis (SSc) and polymyositis since 2019 with immunological (anti-nuclear antibodies with a homogeneous nucleolar pattern in a titer of $1 / 1000$ and an expanded profile of specific myositis and SSc antibodies showing strong positivity for anti-SCL70 and anti-PM/SCL100) diffuse cutaneous, articular, vascular, gastrointestinal, and muscle involvement with an elevation of muscle enzymes, proximal muscle strength deficit of her lower limbs, and skeletal muscle edema on magnetic resonance (MR) at the time of diagnosis. Currently, she was taking nifedipine $30 \mathrm{mg} /$ day and methotrexate $15 \mathrm{mg} /$ week.

She presented to the emergency department with a tight squeezing chest pain, arrhythmic cardiac auscultation, and bilateral pulmonary crackles. Upon admission, we observed normal blood pressure and a heart rate of 150 beats per minute. Laboratory investigations revealed a serum troponin $\mathrm{T}$ level of $0.015 \mathrm{ng} / \mathrm{mL}$ (normal value $<0.016 \mathrm{ng} / \mathrm{mL}$ ) and serum brain natriuretic peptide (BNP) was $1002.3 \mathrm{pg} / \mathrm{mL}$ $(<100.0 \mathrm{pg} / \mathrm{mL})$. Her electrocardiogram showed an atrial flutter with a rapid ventricular response. The transthoracic echocardiogram revealed moderate dilatation of the cardiac chambers with biventricular dysfunction (left ventricular ejection fraction 22\%). Cardiac catheterization showed normal coronary arteries. Chemical cardioversion with amiodarone was performed with restoration of sinus rhythm. Cardiac MR revealed dilatation of the four cardiac chambers with improving biventricular dysfunction.

One week later, a myocardial biopsy showed alterations of a lymphocytic myocarditis (Fig. 1). We have done extensive PCR and RT-PCR testing for cardiotropic viruses that were negative.

She was started on treatment with monthly cyclophosphamide (CYC) $1000 \mathrm{mg}$ with a good clinical and analytical response. Currently, she is on her seventh administration without any signs or symptoms of heart failure and her BNP is $108 \mathrm{pg} / \mathrm{mL}$. No evidence of post-treatment complications or clinical recurrence thus far.

\section{Discussion}

This is to the authors' knowledge on the first histologically proven myocarditis in the context of a myositis SSc overlap. In the literature, there are conflicting data about disease features of SSc overlap, often lacking consistency. However,

Salomé Garcia

salomefernandesgarcia@gmail.com

1 Rheumatology Department, Centro Hospitalar Universitário de São João, Porto, Portugal

2 Rheumatology Department, Centro Hospitalar Universitário Do Algarve, Faro, Portugal

3 Rheumatology Department, Centro Hospitalar Vila Nova de Gaia E Espinho, Vila Nova de Gaia, Portugal 
Fig. 1 Histologic section of the left ventricule. Staining hematoxylin and eosin. a Original magnification $\times 50$ and b original magnification $\times 100$. Interstitial edema and extensive lymphocytic infiltrate (arrow) along with myocyte dropout and necrosis

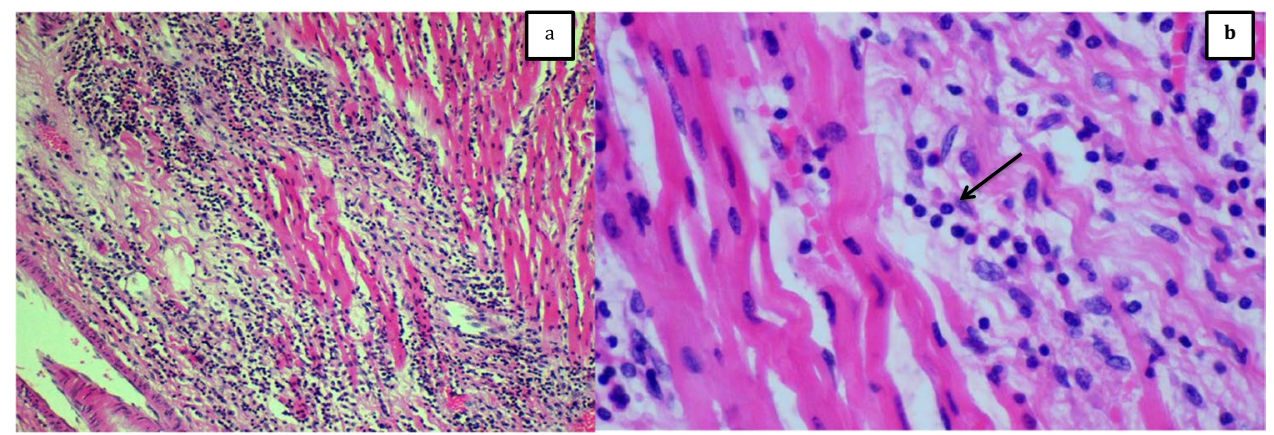

several studies have described increased myocardial involvement in patients with SSc-associated myopathies [1,2].

A better understanding of the differences between SSc and SSc myositis overlap features may lead to improved treatment and prognosis for these patients.

\section{Declarations}

Consent for publication The patient consented with the publication of her case.

Disclosures None.

\section{References}

1. Ranque B, Bérezné A, Le-Guern V, Pagnoux C, Allanore Y, Launay D, Hachulla E, Authier FJ, Gherardi R, Kahan A, Cabane J, Guillevin L, Mouthon L (2010) Myopathies related to systemic sclerosis: a case-control study of associated clinical and immunological features. Scand J Rheumatol 39(6):498-505

2. Moinzadeh P, Aberer E, Ahmadi-Simab K, Blank N, Distler JH, Fierlbeck $G$ et al (2015) Disease progression in systemic sclerosisoverlap syndrome is significantly different from limited and diffuse cutaneous systemic sclerosis. Ann Rheum Dis 74(4):730-737

Publisher's note Springer Nature remains neutral with regard to jurisdictional claims in published maps and institutional affiliations. 